\title{
Wealth Effects with Endogenous Retirement
}

Borys Grochulski and Yuzhe Zhang

I $\mathrm{n}$ this article, we discuss the so-called wealth effects: the response of aggregate consumption to exogenous movements in wealth. Wealth effects are of interest to market participants and policymakers, as they can be informative about expected GDP growth given observed movements in asset prices.

Estimated in a standard way, the wealth effect in aggregate data amounts to about 2.4 cents on the dollar. From the point of view of the simple permanent income theory, as in Friedman (1957), Bewley (1977), or Hall (1978), these estimates are surprisingly low. With changes in asset prices unpredictable, an exogenous increase in wealth of $\$ 1$ increases the agent's permanent income by $r$ dollars, where $r$ is the riskless rate of interest or the agent's rate of time preference. With the standard estimate of $r=5$ percent, permanent income theory predicts the wealth effect of 5 cents on the dollar, which is about twice the effect we observe in the data. ${ }^{1}$

Poterba (2000) reviews the main explanations of weak wealth effects that have been proposed in the literature. At the aggregate level, the response of consumption to wealth changes may be low because wealth concentration is high and consumption of high net worth households may be relatively inelastic. Cagetti and De Nardi (2008) and Saez and Zucman (2016) document a recent further increase in wealth

- The authors thank Caroline Davis, Felipe Schwartzman, Bruno Sultanum, and John Weinberg for their helpful comments and Emma Yeager for excellent research assistance. The views expressed in this article are those of the authors and not necessarily those of the Federal Reserve Bank of Richmond or the Federal Reserve System. Email: borys.grochulski@rich.frb.org; yuzhe-zhang@econmail.tamu.edu.

${ }^{1}$ King and Low (2014) provide estimates of the average world real interest rate of near 5 percent in the 1980s and 1990s, declining after 2000 and strongly so since the financial crisis. The sample we use to estimate wealth effects in Section 1 covers 1958-2018, which does include the period of high real rates identified by King and Low (2014). 
inequality in the US. Using state-level data, Calomiris, Longhofer, and Miles (2012) find a large variation in wealth effects correlated with the dispersion of wealth and age distributions across US states.

At the individual level, the response of consumption to changes in wealth may be weak because wealth is allocated to illiquid assets. Kaplan and Violante (2014) and Saez and Zucman (2016) document that about 80 percent of wealth is held in illiquid assets like housing, retirement accounts, and closely held businesses.

In this article, we discuss another reason why wealth effects may be weak: an endogenous reaction of labor supply along the extensive margin, i.e., retirement. When households save for retirement, their optimal retirement timing decision depends on their wealth. A positive wealth shock can make a household adjust their planned retirement date forward, i.e., shorten the remainder of their work career. But a shorter work career means the present value of all future labor income goes down, which partially offsets the impact of the positive wealth shock on consumption.

Zhao (2018) provides direct evidence on the response of the retirement timing decision to wealth shocks. Using data from the Health and Retirement Study, a panel survey of individuals age fifty and older, he shows that declines in housing prices are positively correlated with a drop in retirement probability for homeowners, while no such correlation exists for renters.

To evaluate quantitatively the impact of the endogenous retirement timing decision on the standard wealth effect, in this article we build a simple model in which the retirement decision is optimally taken according to a threshold policy: the agent retires when her financial wealth, $W_{t}$, reaches a particular, optimally chosen target level, $W^{*}$. A positive wealth shock, specifically, a positive shock to the rate of return on her financial assets, brings the agent closer to retirement. Correspondingly, the monetary value of her human capital, i.e., the present value of the labor income she expects to earn in the remainder of her career, decreases. The agent's optimal consumption decision, naturally, takes into account her total wealth: the sum of her financial wealth and the monetary value of her human capital. The model captures the effect of the offsetting movement of the value of human capital on the response of consumption to financial wealth shocks. Despite a few strong simplifying assumptions we make to keep the model tractable, the model is able to generate a weak wealth effect, which helps explain why the response of consumption to wealth shocks is weak in the data.

We start in Section 1 by presenting a standard estimate of wealth effects in aggregate consumption and wealth data. Using the quarterly US data on wealth and consumption from 1958 to 2018, we estimate 
Grochulski \& Zhang: Wealth Effects with Endogenous Retirement 175

the average wealth effect of 2.4 cents on the dollar. This number is in line with standard estimates obtained in the literature, as summarized in Poterba (2000).

In Section 2, we lay out a stylized model of optimal consumption, saving, and retirement decisions, which essentially is a simplified version of Kingston (2000) and Farhi and Panageas (2007). We follow these studies, in particular, in assuming that the retirement decision is irreversible. $^{2}$

In Section 3, as a baseline, we show that when the retirement decision margin is shut down, our model predicts a wealth effect of $r$ cents on the dollar, in line with the simple permanent income theory. In the baseline case, in particular, the agent does not have an active retirement margin because she is already retired. The value of her human capital is therefore nil and all her wealth is financial. With a logarithmic utility function and Brownian motion wealth return shocks, we can solve the baseline case in closed form.

In Sections 4 and 5, we solve the model with an endogenous retirement decision. We show that if the rate of return on wealth is sufficiently high, the agent prefers to retire if and when her wealth reaches a target level, $W^{*}$. We discuss the Hamilton-Jacobi-Bellman (HJB) equation for the agent's lifetime utility value function, along with a procedure for finding appropriate boundary conditions.

In Section 6, we discuss the dynamics of the monetary value of the agent's human capital in the solution to her optimal consumption, saving, and retirement problem. The main observation there is that, with the retirement decision taken according to a wealth-threshold policy, the value of human capital decreases when the agent's wealth increases. The key part of the computation of the value of human capital at any point in time is the expected remaining duration of the agent's career, i.e., the amount of time left until retirement. We present a useful lemma that allows for computation of this object in our model.

In Section 7, we analyze a special case of our model in which the expected growth rate of financial wealth is equal to the agent's rate of time preference, $r$. We use this special case to show clearly the intuition for our main result: the value of human capital responds negatively to wealth shocks, making the response of consumption weaker. In the special case, in particular, the endogenous response of the value of human capital perfectly offsets all shocks to financial wealth prior to retirement, making the agent's total wealth and consumption constant up until the retirement date. With constant consumption, clearly, the

\footnotetext{
${ }^{2}$ In Section 9, we comment on how our results would change if our model allowed for unretirement.
} 
Table 1 Sample Properties of Aggregate Real Consumption and Net Wealth

\begin{tabular}{lcc}
\hline & $\begin{array}{c}\text { Average } \\
\text { growth rate }\end{array}$ & $\begin{array}{c}\text { St. dev. of } \\
\text { growth rate }\end{array}$ \\
\hline Consumption & $2.9 \%$ & $2.4 \%$ \\
Net Wealth & $3.4 \%$ & $4.4 \%$ \\
\hline
\end{tabular}

offsetting response of the value of human capital is strong enough to make the wealth effect nil at all times during the agent's work career.

Our main results are presented in Section 8, where we calibrate the model to match the wealth effect of 2.4 cents on the dollar, as in the data. The model is capable of generating realistic wealth effects under a reasonable parametrization. The untargeted wealth threshold $W^{*}$ associated with the desired wealth effect is close to sixteen times annual income. We discuss the key intuition of our model showing that the endogenous response of human capital dampens the response of consumption to wealth shocks in the model.

Section 9 concludes with a discussion of the robustness of our results to several of our simplifying assumptions. There, also, we discuss some further related literature.

\section{MEASUREMENT}

In this section, we present briefly the data and conduct a simple estimation of the average wealth effect, similar to Iacoviello (2011). Our point estimate is 2.4 cents on the dollar.

The data consist of the series of quarterly aggregate net wealth and quarterly aggregate consumption expenditure. Net wealth data come from the Flow of Funds. Our sample covers the period of 1952:Q1 though 2018:Q3.

The two variables used in the estimation of wealth effects are as follows:

$N W_{t}=$ Households and Nonprofit Organizations total assets less total liabilities, constant 2005 dollars (CPI deflated).

$C_{t}=$ Personal Consumption Expenditure, constant 2005 dollars (CPI deflated).

Figure 1 plots these two series in levels (millions of constant 2005 dollars) and in year-over-year growth rates. In levels, the ratio of sample average net wealth to consumption is 6.1 . The summary statistics for the growth rates are in Table 1. 
Grochulski \& Zhang: Wealth Effects with Endogenous Retirement 177

Figure 1 Aggregate Real Consumption and Net Wealth

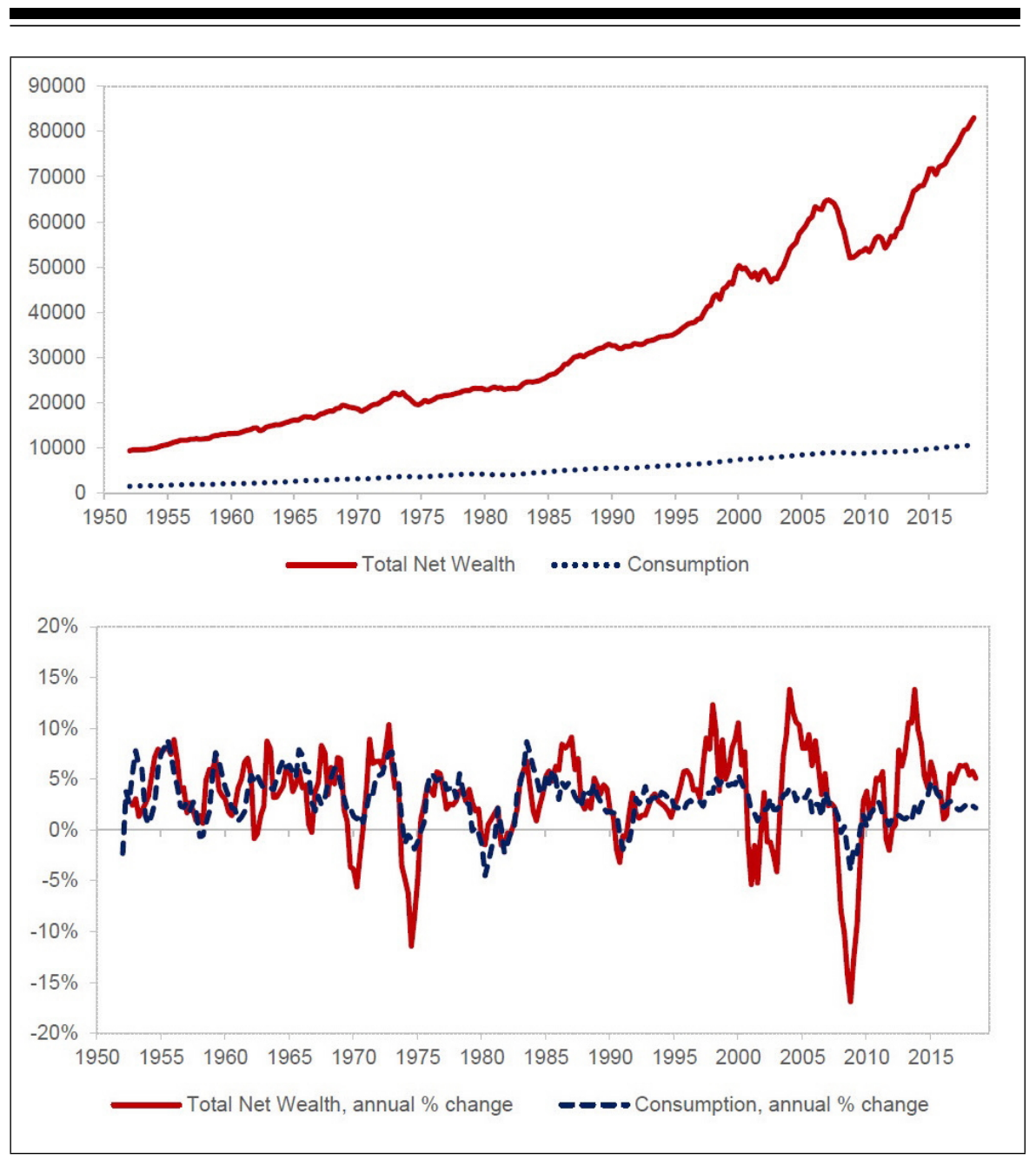

Notes: Top panel: millions of 2005 dollars. Bottom panel: annualized growth rates.

Following Iacoviello (2011), we obtain the average wealth effect by estimating the following regression equation:

$$
\triangle \ln \left(C_{t}\right)=\underset{(.0005)}{.0060}+\underset{(.0286)}{.1475} \triangle \ln \left(N W_{t-1}\right),
$$

where $\triangle$ denotes the first difference operator. With the average net wealth to consumption ratio of 6.1 , the estimated elasticity of consump- 
tion to net wealth of 0.1475 gives the wealth effect of 2.4 cents on the dollar. $^{3}$

Several other ways of measuring wealth effects have been considered in the literature. In a sample that ends in 2008:Q4, Iacoviello (2011) estimates a similar wealth effects regression after splitting net wealth into unencumbered housing wealth and net financial wealth. In that regression, he finds overall wealth effects of similar total magnitude, with the effects of changes in the unencumbered housing wealth component being stronger than those estimated for net nonhousing wealth. Piazzesi and Schneider (2016) provide additional discussion of the effects of housing price changes on consumption. The studies reviewed in Poterba (2000) suggest that a $\$ 1$ increase in stock market equity values raises consumption in the next quarter by 2 cents, while an analogous increase in non-stock-market wealth raises next-quarter consumption by 1.4 cents. $^{4}$

In our analysis, we will take the average wealth effect of 2.4 cents on the dollar as our target. Using a simple model of optimal consumption, saving, and retirement decisions, we will show how an endogenous response of labor supply along the extensive margin can bring the wealth effect from the baseline level of 5 cents on the dollar down to the estimated value of 2.4 cents.

\section{MODEL}

Consider the following optimal consumption and saving problem. The retirement decision will be added in Section 3. The agent has initial financial wealth $W_{0}$. For simplicity, we will abstract from the agent's portfolio decision of allocating her wealth between different asset classes and instead treat financial wealth as a single, aggregated asset to which

\footnotetext{
${ }^{3}$ Following Iacoviello (2011), we calculate the average dollar-over-dollar wealth effect from the average elasticity of consumption with respect to net wealth and the average ratio of net wealth to consumption:

$$
\frac{\triangle C}{\triangle N W}=\frac{\frac{\triangle C}{C}}{\frac{\triangle N W}{N W}} \frac{C}{N W}=\frac{\triangle \ln (C)}{\triangle \ln (N W)} \div \frac{N W}{C} .
$$

${ }^{4}$ See, however, Lettau and Ludvigson (2004), who argue that net worth changes have a significant transitory component, which makes identification of wealth effects not straightforward.
} 
Grochulski \& Zhang: Wealth Effects with Endogenous Retirement 179

all wealth is allocated. ${ }^{5}$ We will refer to this asset simply as financial wealth and denote the amount held by the agent at date $t$ by $W_{t}{ }^{6}$

We assume that the expected growth rate and volatility of financial wealth are constant and denote them, respectively, by $\mu$ and $\sigma$. That is, absent any new investments or withdrawals, the agent's financial wealth follows geometric Brownian motion

$$
d W_{t}=\mu W_{t} d t+\sigma W_{t} d Z_{t},
$$

where $Z_{t}$ is a cumulative growth rate shock process modeled as standard Brownian motion on a probability space $(\Omega, \mathcal{F}, P)$.

The agent draws utility from two sources: consumption of a single consumption good and leisure that the agent enjoys in retirement. The agent's flow of utility from consumption is $u\left(c_{t}\right)$, where $u$ is her utility function. To facilitate analytical solutions, we will often assume logarithmic utility: $u=\ln$. The agent's flow utility from leisure in retirement is denoted by $\psi>0$. If not retired, the agent does not receive $\psi$ but earns labor income $y>0$, which, again for simplicity, we will take to be constant. ${ }^{7}$ The agent discounts future payoffs at a constant rate of time preference $r>0$.

Our simplifying assumption of a single financial asset will force the agent to take on risk as she saves. In particular, our model does not allow the agent to save by investing in a riskless asset. To ensure that this feature of the model does not drive our results, we will assume that the expected growth rate of financial wealth is sufficiently positive.

Assumption $1 \mu-r>\frac{1}{2} \sigma^{2}$.

\section{WEALTH EFFECTS WITHOUT SAVING FOR RETIREMENT}

In this section, we use our model of optimal consumption and saving decisions to derive optimal wealth effects in the absence of an endogenous retirement decision. In particular, for simplicity and also as a building block for the foregoing analysis, we assume in this section that the agent is already retired.

\footnotetext{
${ }^{5}$ See Kingston (2000) and Farhi and Panageas (2007) for related models with a portfolio choice.

${ }^{6}$ Alternatively, we can interpret $W_{t}$ as physical capital that can be converted to and from consumption without any transaction costs, so the price of capital in terms of current consumption is always 1 .

7 This assumption is not essential for the main mechanism of our model to work. We discuss this point briefly in the concluding Section 9.
} 
In retirement, as the agent does not earn any labor income, her financial wealth $W_{t}$ evolves according to

$$
d W_{t}=\left(\mu W_{t}-c_{t}\right) d t+\sigma W_{t} d Z_{t},
$$

where $c_{t}$ is the agent's consumption flow at date $t$. The agent also receives the flow of leisure utility $\psi$.

Let us denote by $V(W)$ the maximal value that the agent can attain in retirement given that her current financial wealth is $W$. That is, the value function $V$ is defined as

$$
V(W):=\max _{\left\{c_{t} ; t \geq 0\right\}} \mathbb{E}\left\{\left[\int_{0}^{\infty} e^{-r t}\left(u\left(c_{t}\right)+\psi\right) d t\right] \text { s.t. (2) and } W_{0}=W,\right.
$$

where expectation is taken over the realizations of the financial return shock $Z_{t}$. Note that the expression for the agent's total discounted expected utility takes into account the flow of leisure utility in retirement $\psi$.

In the remainder of this section, we will characterize the agent's optimal consumption plan and compute the wealth effect, which shows how the agent's consumption responds to changes in wealth.

\section{HJB equation for the value of retirement}

To find the agent's optimal consumption policy, we will use dynamic programming. ${ }^{8}$ The intuition behind this approach is as follows. If the agent optimally chooses her consumption, then the flow of value she receives out of financial wealth $W_{t}$ consists of the current utility flow from consumption and leisure plus the increase in the value she expects going forward. This intuition is succinctly expressed in the following equation:

$$
\left.r V\left(W_{t}\right) d t=\max _{c}\left\{(u(c)+\psi) d t+\mathbb{E}\left[d V\left(W_{t}\right)\right]\right\}\left[d V\left(W_{t}\right)\right]\right\} .
$$

Equivalently, we can divide both sides by $V\left(W_{t}\right)$ and note that this condition implies that the rate of return the agent earns in value terms is equal to her rate of time preference $r d t$. The agent's rate of return consists of the "dividend yield" component $(u(c)+\psi) d t / V\left(W_{t}\right)$ and the expected "capital gain" component $\mathbb{E}\left[d V\left(W_{t}\right)\right] / V\left(W_{t}\right)$.

Assuming that $V$ is twice continuously differentiable, we can use Ito's lemma (see, e.g., Karatzas and Shreve 1998) to compute the expected time change in the value $V$, given that financial wealth follows

\footnotetext{
${ }^{8}$ For a standard textbook exposition of dynamic programming and Bellman equations, see Dixit (1990) or Kamien and Schwartz (1991). For additional details on the derivation of HJB equations in a related setting, see Grochulski and Zhang (2013).
} 
Grochulski \& Zhang: Wealth Effects with Endogenous Retirement 181

(2) and the agent consumes at rate $c d t$ :

$$
\mathbb{E}\left[d V\left(W_{t}\right)\right]=\left(\left(\mu W_{t}-c\right) V^{\prime}\left(W_{t}\right)+\frac{1}{2} \sigma^{2} W_{t}^{2} V^{\prime \prime}\left(W_{t}\right)\right) d t .
$$

Clearly, a higher consumption rate, $c d t$, implies lower wealth tomorrow, which, given that the agent's value function is increasing in financial wealth, $V^{\prime}>0$, implies a lower change in the agent's value going forward. On the other hand, as we see in (3), the agent's current utility flow is higher when $c$ is higher. This trade-off is captured by the HJB equation for the value function $V$, which we obtain by substituting (4) into (3):

$$
r V\left(W_{t}\right)=\max _{c}\left\{u(c)+\psi+\left(\mu W_{t}-c\right) V^{\prime}\left(W_{t}\right)+\frac{1}{2} \sigma^{2} W_{t}^{2} V^{\prime \prime}\left(W_{t}\right)\right\} .
$$

We will use this equation to find the value function $V$ next.

\section{Solution to the optimal consumption problem in retirement}

With logarithmic utility of consumption, we can solve the retirement value problem in closed form.

Proposition 1 Suppose $u(c)=\ln (c)$, then the retirement value function $V$ is given by

$$
r V\left(W_{t}\right)=\ln \left(r W_{t}\right)+\psi+r^{-1}\left(\mu-r-\frac{1}{2} \sigma^{2}\right) .
$$

To verify the solution in (6), we compute its first and second derivative as

$$
V^{\prime}\left(W_{t}\right)=\frac{1}{r W_{t}} \text { and } V^{\prime \prime}\left(W_{t}\right)=\frac{-1}{r W_{t}^{2}} .
$$

We then use $u=\ln$ and take the first-order condition with respect to $c$ in (5):

$$
\frac{1}{c}=V^{\prime}\left(W_{t}\right)
$$

which implies $u(c)=-\ln \left(V^{\prime}\left(W_{t}\right)\right)$. We can then write (5) as

$$
r V\left(W_{t}\right)=-\ln \left(V^{\prime}\left(W_{t}\right)\right)+\psi+\mu W_{t} V^{\prime}\left(W_{t}\right)-1+\frac{1}{2} \sigma^{2} W_{t}^{2} V^{\prime \prime}\left(W_{t}\right) .
$$

When we substitute the derivatives in (7) to the right-hand side of the above equation, we verify (6).

If we suppose that financial wealth is a safe asset with the riskless growth rate equal to the agent's rate of time preference, i.e., if $\mu=r$ 
and $\sigma=0$, then, due to the desire for consumption smoothing, the agent's optimal consumption policy would be to consume a constant amount at all dates in retirement. With wealth $W$, the maximal constant consumption the agent can afford is $c=r W$, which keeps the agent's wealth constant. The value the agent would attain in these conditions thus satisfies $r V(W)=\ln (r W)+\psi$.

Comparing this value with (6), we see that the constant $r^{-1}(\mu-$ $\left.r-\frac{1}{2} \sigma^{2}\right)$ represents the impact that the excess expected return $\mu-r$ and volatility $\sigma$ have on the value the agent attains when the growth rate of wealth is risky, as in (2). Assumption 1 ensures that, despite the risk in the growth rate of the only asset available to the agent in retirement, she is able to attain a higher value than she would with a riskless asset. This attenuates the concern that our results are driven by our simplifying assumption of no riskless asset in the model.

\section{Wealth effects in retirement}

We can now use the closed-form solution for $V$ to compute the agent's optimal consumption and the associated wealth effect in retirement. Using the first-order condition in (8) and the marginal value of wealth in (7), we obtain that the agent's optimal consumption satisfies

$$
c_{t}=r W_{t}
$$

That is, the agent consumes a constant fraction of her wealth at all times. While this policy is the same as the one the agent would choose if the growth rate of wealth was riskless, the value the agent attains, of course, is lower due to risk.

With the agent's consumption function given in closed form in (9), we immediately obtain the wealth effect, or the marginal propensity to consume out of wealth, given as

$$
\frac{d c_{t}}{d W_{t}}=r
$$

In a typical calibration, we would have $r=0.05$, which implies a wealth effect of 5 cents on the dollar. This number is about twice what we estimated in Section 1. In the remainder of this article, we will argue that this number is made lower, and thus closer to the wealth effects observed in the data, when an endogenous labor supply decision is taken into account. In particular, we focus on the extensive margin of labor supply, i.e., work versus retirement. 
Grochulski \& Zhang: Wealth Effects with Endogenous Retirement 183

\section{WORKING FOREVER}

Before we consider, in the next section, the wealth effects while the agent saves for retirement, in this section we discuss the option of never retiring, i.e., working forever. We argue that the plan to never retire is not optimal for the agent. In particular, we show that when the agent's wealth is high enough, being permanently retired is preferable to permanently working. This means that the agent's optimal retirement plan is a threshold policy, where the agent retires as soon as her wealth reaches a certain level, which we analyze in the next section.

While working, the agent earns labor income $y$, assumed here to be constant, and decides at each point in time how much to consume out of $y$ and out of her stock of financial wealth $W_{t}$. The law of motion for the agent's financial wealth $W_{t}$ is as follows

$$
d W_{t}=\left(\mu W_{t}+y-c_{t}\right) d t+\sigma W_{t} d Z_{t} .
$$

If, for example, the agent were to consume exactly her labor income at all times, i.e., if $c_{t}=y$, then her financial wealth would follow simply geometric Brownian motion (1).

Denote by $F(W)$ the maximal value that the agent whose wealth is $W$ can obtain by never retiring, i.e., working and earning the flow of income $y$ forever, while saving and consuming optimally. That is

$$
F(W):=\max _{\left(c_{t} ; t \geq 0\right)} \mathbb{E}\left[\int_{0}^{\infty} e^{-r t} u\left(c_{t}\right) d t\right] \text { s.t. }(10) \text { and } W_{0}=W .
$$

The main result of this section is the following

Proposition 2 There exists $\bar{W}$ such that $F(W)<V(W)$ for all $W \geq$ $\bar{W}$.

In words, when financial wealth is sufficiently high, the agent would rather be permanently retired than permanently working.

We argue this result by making use of an auxiliary result. Let us define and denote by $V_{0}$ the value of being retired but without the utility flow of leisure:

$$
V_{0}(W):=\max _{\left(c_{t} ; t \geq 0\right)} \mathbb{E}\left[\int_{0}^{\infty} e^{-r t} u\left(c_{t}\right) d t\right] \text { s.t. }(2) \text { and } W_{0}=W .
$$

Because this function is a special case of the retirement value function $V$, one in which $\psi=0$, we know that $V_{0}(W)=V(W)-\frac{\psi}{r}$. Note that this means that $V_{0}^{\prime}(W)=\frac{1}{r W}$, which is the same as $V^{\prime}(W)$ because the flow utility of leisure $\psi$ enters $V$ additively.

Our auxiliary result is as follows:

Lemma $1 \lim _{W \rightarrow \infty} F(W)=V_{0}(W)$. 
The following sketch of the formal argument for why this is true captures the intuition. Directly from the definition of function $F$ and the function $V_{0}$, we see that these two values come out of maximizing the same objective subject to two different laws of motion for financial wealth. In the case of $F$, the law of motion includes labor income $y$. Like we did earlier for $V$, we can write an HJB equation for $F$ as follows

$$
r F\left(W_{t}\right)=\max _{c}\left\{u(c)+F^{\prime}\left(W_{t}\right)\left(\mu W_{t}+y-c\right)+\frac{1}{2} \sigma^{2} W_{t}^{2} F^{\prime \prime}\left(W_{t}\right)\right\} .
$$

We can see that the contribution of $y$ to $F$ is $F^{\prime}(W) y$, where $F^{\prime}(W)$ represents the marginal valuation of $y$ at wealth $W$. Next, we observe that this marginal valuation must be smaller than $V_{0}^{\prime}(W)$, which is how income $y$ would be valued by an agent who does not have it. Therefore, we must have $F^{\prime}(W) y<V_{0}^{\prime}(W) y=\frac{y}{r W}$, which goes to zero as $W$ goes to infinity. Thus, the difference between $F$ and $V_{0}$ must go to zero as wealth approaches infinity, which proves the lemma. Intuitively, when the stock of her financial wealth becomes larger and larger, whether or not the agent earns some constant labor income $y$ matters less and less and becomes immaterial when financial wealth is sufficiently large.

Lemma 1 implies Proposition 2 because

$$
V_{0}(W)+\frac{\psi}{r}=V(W) .
$$

Clearly, since $F(W)$ coverages to $V_{0}(W)$ as $W$ becomes large, $F(W)$ must fall below $V_{0}(W)+\frac{\psi}{r}$ at some point. This point is represented by $\bar{W}$ in the statement of Proposition 2.

In sum, we have argued in this section that when the agent's financial wealth is high enough, she prefers being permanently retired to working forever. In the next section, we will use this fact when we define and solve the agent's problem of optimal saving for retirement.

\section{SAVING FOR RETIREMENT}

In this section, we define the consumption and saving problem with endogenous retirement and describe the method for solving it. Since retirement is irreversible in our model, the choice of the optimal timing of retirement is a real-option exercise problem similar to the exercise problems studied in the investment literature. ${ }^{9}$

Let us define and denote by $J(W)$ the maximum lifetime utility an agent with financial wealth $W$ can attain by working and retiring at

\footnotetext{
${ }^{9}$ See, for example, Pindyck (1991).
} 
Grochulski \& Zhang: Wealth Effects with Endogenous Retirement 185

some point in the future. That is,

$J(W):=\max _{\left(c_{t} ; t \geq 0\right), \tau} \mathbb{E}\left[\int_{0}^{\tau} e^{-r t} u\left(c_{t}\right) d t+e^{-r \tau} V\left(W_{\tau}\right)\right]$ s.t. (10) and $W_{0}=W$,

where $\tau$ is the agent's preferred retirement time, $V\left(W_{t}\right)$ is the value of retiring with wealth $W_{t}$, and the expectation $\mathbb{E}$ is taken over the realizations of the wealth growth shock process $Z_{t}$. As we see, the agent's utility flow before retirement does not include the value of leisure, $\psi$, and the law of motion for financial wealth accounts for the agent's labor income $y$.

As we did for $V$ and $F$, we can use dynamic programing to obtain the following HJB equation for $J$

$$
r J\left(W_{t}\right)=\max _{c}\left\{u(c)+J^{\prime}\left(W_{t}\right)\left(\mu W_{t}+y-c\right)+\frac{1}{2} \sigma^{2} W_{t}^{2} J^{\prime \prime}\left(W_{t}\right)\right\} .
$$

Since HJB equations only account for the local flows of utility and changes in wealth, the HJB equations $F$ and $J$ are the same. The difference between the optimal value functions $F$ and $J$ comes from their boundary conditions, which we discuss next.

\section{Boundary conditions and existence of optimal solution}

At $W_{t}=0$, the HJB equation simplifies to $r J(0)=\max _{c}$ $\left\{u(c)+J^{\prime}(0)(y-c)\right\}$. The first-order condition for consumption with $u=\ln$ gives us, as before, $c=1 / J^{\prime}(0)$ and $u(c)=-\ln \left(J^{\prime}(0)\right)$. Substituting to the HJB, we obtain a boundary condition for $J$ :

$$
r J(0)=-\ln \left(J^{\prime}(0)\right)+J^{\prime}(0) y-1 .
$$

Since we do not allow negative financial wealth, drift of $W_{t}$ cannot be negative when $W_{t}=0$. That is, the agent must be saving a part of her labor income when $W_{t}=0$, i.e., we must have $c \leq y$, which gives us a restriction on the slope of $J$ at zero: $J^{\prime}(0)=\frac{1}{c} \geq \frac{1}{y} \cdot{ }^{10}$

Using the boundary condition (12), we can solve the HJB equation forward from the boundary point $W=0 .{ }^{11}$ This gives us a unidimensional family of solution curves $J(W)$, indexed by $J^{\prime}(0) \geq \frac{1}{y}$.

\footnotetext{
${ }^{10}$ As a side note, we also know that $r J(0) \geq u(y)$ because the agent with zero financial wealth has the option to consume $c=y$ and work forever.

${ }^{11}$ Because volatility of financial wealth is zero when wealth itself is zero, advancing the solution out of $W=0$ presents a challenge for numerical ODE solvers. This challenge can be quite easily overcome by using local or global numerical approximation methods.
} 
The analysis of the value of working forever, discussed in the previous section, implies here that solution curves $J(W)$ that remain strictly above the curve $V(W)$ for all $W$ can be classified as inadmissible. Indeed, since $V$ represents the value of being retired, if a solution curve $J$ such that $J(W)>V(W)$ for all $W$ were to represent the maximum utility value the agent could obtain, then it would be optimal for the agent to never retire, i.e., to set $\tau=\infty$. But we know from the previous section that the value of working forever, denoted by $F(W)$, is not above $V(W)$ for all $W$, which gives us a contradiction. Thus, admissible solutions $J$ are those that satisfy the boundary condition (12) at $W=0$ and satisfy $J(W)=V(W)$ for some $W$. The highest of the admissible solutions is the optimal one.

It can be shown that the maximum admissible $J$ exists, that it satisfies $J(W) \geq V(W)$ for all $W$, and that the set of $W$ on which $J(W)=V(W)$ consists of just a single point. Intuitively, if there is more than one point in this set, we can shift the curve $J$ up to obtain a better admissible solution. We can continue this process until a single point remains in the set on which $J$ overlaps with $V$. That point, which we will denote by $W^{*}$, is when the agent optimally chooses to retire.

The agent's optimal retirement time $\tau$ is thus a stopping time. That is, the agent works until her financial wealth attains the threshold $W^{*}$ for the first time, and she retires at that time. The retirement date, thus, satisfies

$$
\tau=\min \left\{t: W_{t}=W^{*}\right\}
$$

Geometrically, since $W^{*}$ is the single point on which $J$ and $V$ overlap, in addition to the values $J\left(W^{*}\right)$ and $V\left(W^{*}\right)$ being the same, the first derivatives must match, $\left.\left.J^{\prime *}\right)=V^{*}\right)$, and $J$ must be less concave than $V$ at $W^{*}$, i.e., $J$ must have a less negative second derivative than $V$ at the retirement threshold. ${ }^{12}$

In sum, the procedure for finding the optimal solution $J$ is as follows. Start with some $J^{\prime}(0)$ close to $1 / y$ and use the boundary condition (12) to determine $J(0)$. Solve the HJB equation forward from zero. If $J^{\prime}(0)$ is close enough to $1 / y$, this solution will at some $W$ cross the value of being retired, $V$. Increase $J^{\prime}(0)$ to obtain a new solution curve, which is everywhere above the one obtained from the initial guess. Repeat until the solution $J$ becomes tangent to $V$. The point of tangency becomes the optimal wealth retirement threshold $W^{*}$.

\footnotetext{
${ }^{12}$ Our construction of the optimal solution curve $J$ provides a simple example of how the so-called smooth-pasting optimality conditions arise in many optimal control problems. For a much more extensive discussion of these conditions, see Dixit (1993).
} 
Grochulski \& Zhang: Wealth Effects with Endogenous Retirement 187

\section{THE ENDOGENOUS VALUE OF HUMAN CAPITAL}

In this section, we discuss the impact of wealth shocks on the value of the agent's human capital when retirement is endogenous.

Generally, the value of one's human capital is defined as the expected present value of all of one's future labor earnings. ${ }^{13}$ Following this definition and denoting the value of the agent's human capital at time $t$ by $H_{t}$, we have

$$
H_{t}:=\mathbb{E}_{t}\left[\int_{0}^{\tau} e^{-r s} y d s\right],
$$

where $\tau=\min \left\{t: W_{t}=W^{*}\right\}$ is the agent's retirement date. Because income $y$ is constant in our model as long as the agent is working, we have

$$
H_{t}=\frac{y}{r} \mathbb{E}_{t}\left[\int_{0}^{\tau} r e^{-r s} d s\right]=\frac{y}{r}\left(1-\mathbb{E}_{t}\left[e^{-r \tau}\right]\right)=\frac{y}{r}\left(1-G\left(W_{t}\right)\right),
$$

where

$$
G\left(W_{t}\right):=\mathbb{E}_{t}\left[e^{-r \tau}\right]
$$

is the expected discount factor from the present until retirement.

Clearly, the value of the agent's human capital is endogenous with respect to her retirement decision. When her financial wealth hits $W^{*}$, the agent retires immediately, which means $\tau=0$ and $G\left(W^{*}\right)=$ $E_{t}\left[e^{0}\right]=1$. Thus, $H_{t}=0$ when $W_{t}=W^{*}$. At the other extreme, suppose, as we did when we discussed the value function $F$, that the agent chooses to never retire, i.e., sets $\tau=\infty$. In this case, the value of the agent's human capital is constant at all dates and states: $H_{t}=\frac{y}{r}$.

As we see, the value of the agent's human capital depends on how soon she expects to retire. This time horizon, in turn, depends on the agent's saving rate and her current financial wealth. But, since savings are also determined by the financial wealth position, we can express the value of human capital as a function of the agent's financial wealth alone: $H_{t}=H\left(W_{t}\right)$. Note that the function $H$ is decreasing: higher $W_{t}$ means nearer retirement, i.e., a shorter remaining career, and thus a lower monetary value of human capital.

As we see in (13), the key part in the computation of $H(W)$ is the function $G$. We have the following

Lemma 2 satisfies $G\left(W^{*}\right)=1$ and

$$
r G(W)=(\mu W+y-c(W)) G^{\prime}(W)+\frac{1}{2} \sigma^{2} W^{2} G^{\prime \prime}(W),
$$

\footnotetext{
${ }^{13}$ See, e.g., the review article by Benzoni and Chyruk (2015).
} 
where $c(W)$ is the agent's optimal consumption policy before retirement.

The differential equation in this lemma accounts for the agent's remaining time before retirement, taking into account the dynamics of her financial wealth position $W_{t}$. In order to capture these dynamics correctly, we need to know the agent's optimal consumption policy $c(W)$, which comes from the value function $J$ characterized in the previous section. We provide a short formal proof of this lemma in the Appendix. ${ }^{14}$

\section{SPECIAL CASE WITH NO RISK PREMIUM}

In this section, we discuss briefly a special case in which $\mu=r$, i.e., the case in which aggregate wealth offers no risk premium. This case admits a closed-form solution to the problem of optimal consumption and saving for retirement and provides a clear illustration of our point that wealth effects are weaker when retirement is endogenous.

However, this special case violates Assumption 1. The results of this section, therefore, need to be taken with caution. In particular, the agent's only vehicle for saving in this section is an asset that offers zero excess return and positive risk. Such an asset would clearly be dominated by a riskless asset with the expected rate of return equal to the agent's rate of time preference. In practice, even if such a completely safe asset is not available, close substitutes are. To ensure that, despite this low risk-adjusted return of the financial asset, the agent wants to save for retirement, in this section we impose a stronger assumption on the value of leisure in retirement.

Assumption $2 \psi>1+\frac{\sigma^{2}}{2 r}$.

Under this assumption, as we show next, the agent wants to save for retirement even though the asset she can use is risky and offers no excess return.

Proposition 3 Under Assumption 2, if $u=\ln$ and $\mu=r$, then $J$ is linear:

$$
J\left(W_{t}\right)=V\left(W^{*}\right)+V^{\prime}\left(W^{*}\right)\left(W_{t}-W^{*}\right),
$$

where

$$
W^{*}=\frac{y}{r \psi-\frac{1}{2} \sigma^{2}}
$$

\footnotetext{
${ }^{14}$ For a textbook treatment of expected hitting times in Brownian models, see Stokey (2009).
} 
Grochulski \& Zhang: Wealth Effects with Endogenous Retirement 189

The agent's optimal consumption and total wealth are constant at all times prior to retirement:

$$
c_{t}=r W^{*} \text { and } W_{t}+H\left(W_{t}\right)=W^{*} \text { at all } t \leq \tau .
$$

To verify the value function in (15), we can differentiate it and substitute to the HJB equation (11) using the retirement value function $V$ given in (6).

The first-order condition for consumption, $u^{\prime}\left(c_{t}\right)=1 / c_{t}=J^{\prime}\left(W_{t}\right)=$ $V^{\prime}\left(W^{*}\right)=r W^{*}$, confirms that the agent consumes a constant amount prior to retirement. The terms in the expression for $W^{*}$ show how the agent's retirement wealth threshold depends on the parameters. Assumption 2 implies that the agent saves: $c_{t}<y$ at all dates prior to retirement. Indeed, $c_{t}=r W^{*}=\frac{y}{\psi-\frac{\sigma^{2}}{2 r}}<y$.

Proposition 3 also shows that the value of the agent's human capital offsets perfectly any shocks to financial wealth as the agent saves for retirement, leaving the agent's total wealth, $W_{t}+H\left(W_{t}\right)$, constant. To verify that indeed $H\left(W_{t}\right)=W^{*}-W_{t}$ at all $t$, we use Lemma 2 to compute the expected discount factor until retirement, $G(W)$. In particular, we can guess and verify by differentiation and substitution to (14) that

$$
G(W)=1-\frac{r}{y}\left(W^{*}-W\right) .
$$

Substituting this expression for $G(W)$ into (13) yields the result.

This result helps us understand why consumption prior to retirement is constant: the agent's total wealth is constant. The agent desires to smooth her consumption of the consumption good but not necessarily her consumption of leisure. For this reason, the shocks to her financial wealth position are absorbed by her supply of labor, on the extensive margin, which allows her to keep total wealth constant and her consumption perfectly smoothed. Clearly, negative shocks to the return on financial wealth still hurt the agent by making her postpone retirement but do not affect her consumption. Likewise, positive shocks improve the agent's value, which we see in (15), where the value function $J$ is strictly increasing in financial wealth.

We conclude this section by noting that constant consumption $c_{t}=$ $r W^{*}$ for any $W_{t}<W^{*}$ implies the wealth effect is nil:

$$
\frac{d c_{t}}{d W_{t}}=0
$$

With no consumption response, the whole financial return risk is absorbed by the agent's present value of future utility from leisure. Indeed, we can substitute (16) and (6) into (15) to express the agent's 
value function prior to retirement as

$$
r J(W)=u\left(r W^{*}\right)+G(W)\left(\psi-\frac{\sigma^{2}}{2 r}\right) .
$$

This formula shows that the expected present value of the agent's consumption, $u\left(r W^{*}\right)$, does not at all respond to changes in financial wealth, and $J$ depends on $W$ only through the expected present value of the utility from leisure in retirement, $G(W) \psi$, and the penalty for risky consumption in retirement, $-G(W) \sigma^{2} / 2 r$.

The zero wealth effect result, although too extreme relative to the wealth effects measured in Section 1, highlights our main point: the endogenous response of labor supply to realized wealth shocks attenuates the impact of these shocks on consumption. In the next section, we calibrate our model to obtain realistic wealth effects consistent with those measured in Section 1.

\section{CALIBRATION FOR REALISTIC WEALTH EFFECTS}

In this section, we show that this model can generate realistic wealth effects of about 2.4 cents on the dollar, as measured in Section 1. We calibrate the model allowing for positive risk premium $\mu>r$ and solve it numerically. We present optimal value functions, consumption policies, and wealth effects.

We normalize the labor income flow $y=1$ and use the standard rate of time preference of $r=0.05$. In order to pick parameters $\mu$

and $\sigma$, we use the average growth rate and the standard deviation of the growth rate of aggregate net wealth presented in Table 1. We will not ask this stylized model to also match the aggregate consumption statistics given in Table 1. Instead, we approximate consumption by using the simple dynamics our model predicts in retirement. That is, we approximate consumption as $c_{t}=r W_{t}$ and substitute it to the law of motion for wealth in retirement (2), which implies the average growth rate of wealth after consumption of $\mu-r$. We calibrate this to match the 3.4 percent reported in Table 1 , which gives us $\mu=0.084$. The volatility parameter for wealth after consumption we calibrate to match the standard deviation of net wealth reported in Table 1, which gives us $\sigma=0.044$. Finally, the parameter $\psi$ is chosen to match our target of the average wealth effects of 2.4 cents on a dollar. The calibrated value of $\psi$ is 1.28 .

Under this parametrization, we solve the model numerically and obtain the optimal value function $J$ using the procedure described in Section 5. The solution, along with the retirement value function $V$ characterized in Proposition 1, is plotted in Figure 2. Clearly, as shown 
Figure 2 Pre- and Postretirement Value Functions

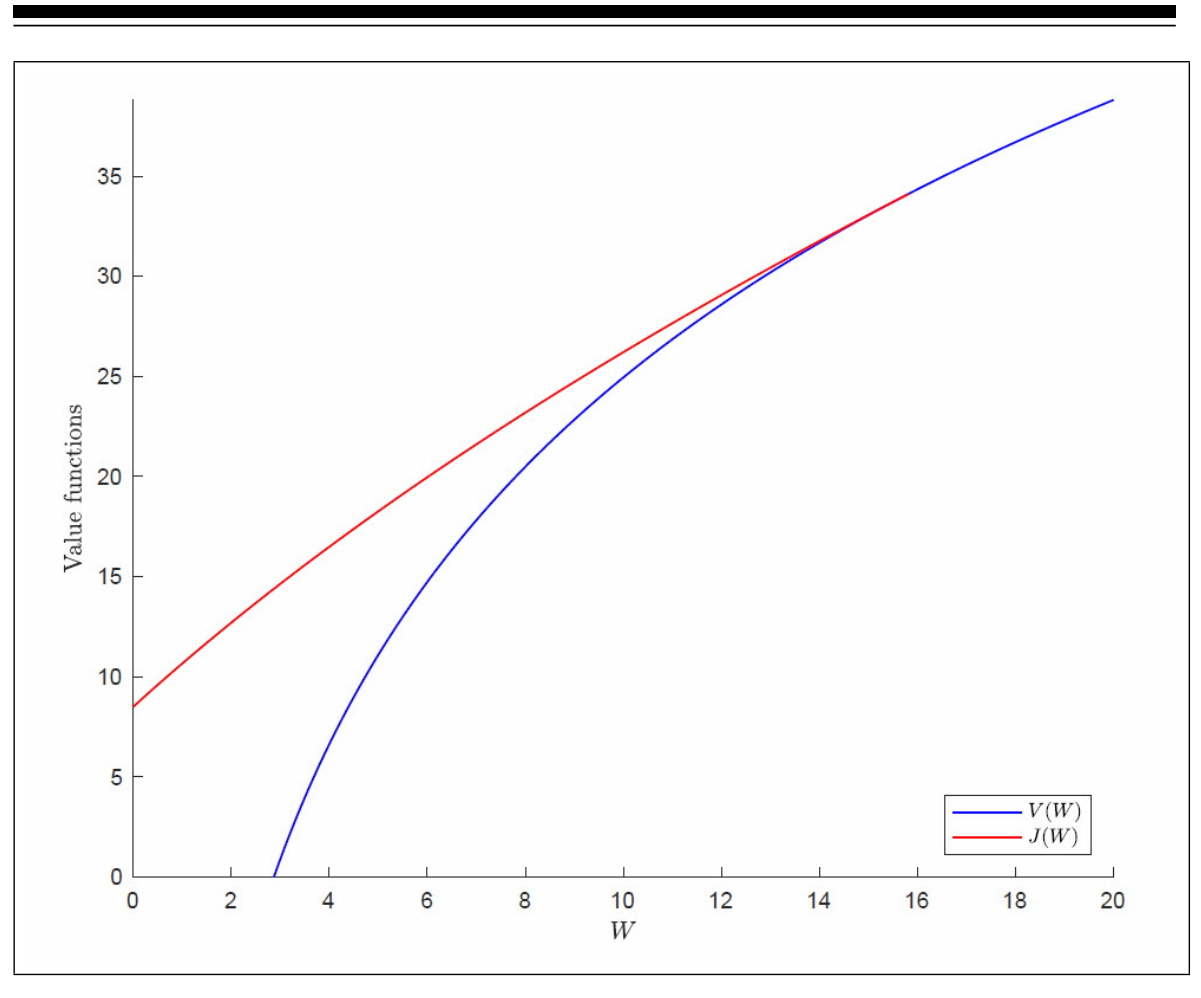

by the vertical difference between $J$ and $V$, the agent's labor income $y$ is most valuable to her when her financial wealth is low. Positive labor income allows the agent to better insulate her consumption from the wealth return shocks $Z_{t}$, consistent with $J$ being everywhere flatter and less concave than $V$. The two value functions paste together at the retirement threshold of $W^{*}=15.8$, which means the agent retires when her financial wealth reaches roughly sixteen times annual income. This number, which did not target in the calibration, may seem high, but this is to be expected of our infinitely lived agent model.

The optimal consumption functions prior to and after retirement are plotted in Figure 3. Consistent with previous observations, consumption is flatter, i.e., less responsive to wealth return shocks, prior to retirement. This shape of the optimal consumption function implies lower wealth effects prior to retirement. In retirement, $c(W)$ has a constant slope equal to $r$. Prior to retirement, this slope is less positive and not exactly constant. 


\section{Figure 3 Optimal Consumption}

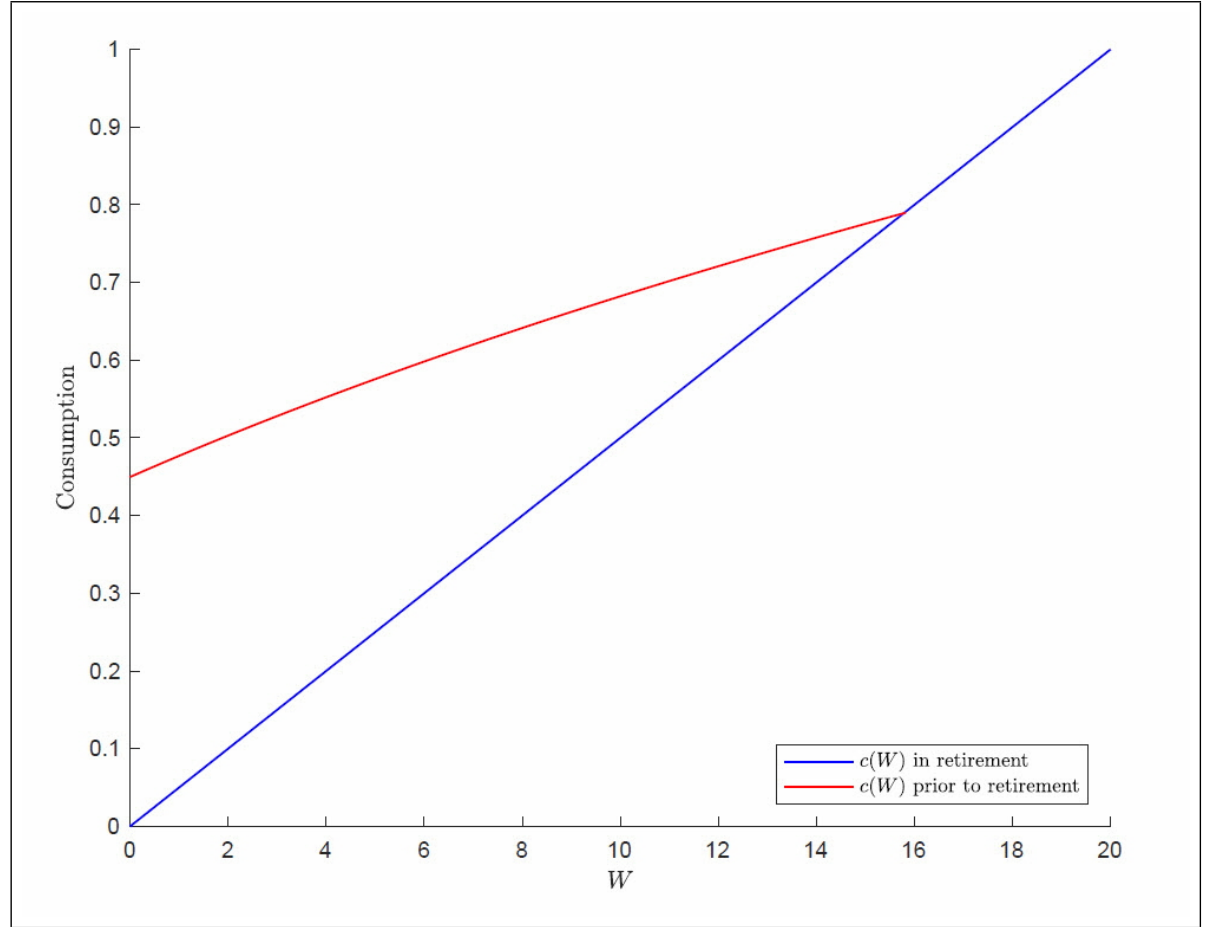

The exact wealth effects, i.e., the slopes of the two consumption functions, are plotted in Figure 4. While constant in retirement, the wealth effects are decreasing in financial wealth prior to retirement, ranging from almost 3 cents on the dollar when wealth is low to a bit below 2 cents when wealth is high. The average of these effects matches the number estimated in Section 1 of 2.4 cents on the dollar. When the agent retires, the wealth effect jumps to 5 cents. This discontinuity comes from the irreversible switching of the agent's state from working to retired as wealth reaches the threshold $W^{*}$.

The intuition for why wealth effects are weaker prior to retirement than after is similar to that of the special case discussed in the previous section: when retirement is endogenous, changes in the value of human capital offset the shocks to the agent's financial wealth, keeping her total wealth relatively more stable, which dampens the response of consumption. In the special case discussed earlier, the offsetting response of the value of human capital was one-to-one: total wealth was constant, the wealth effect for consumption was nil, and the financial 
Grochulski \& Zhang: Wealth Effects with Endogenous Retirement 193

Figure 4 Wealth Effects

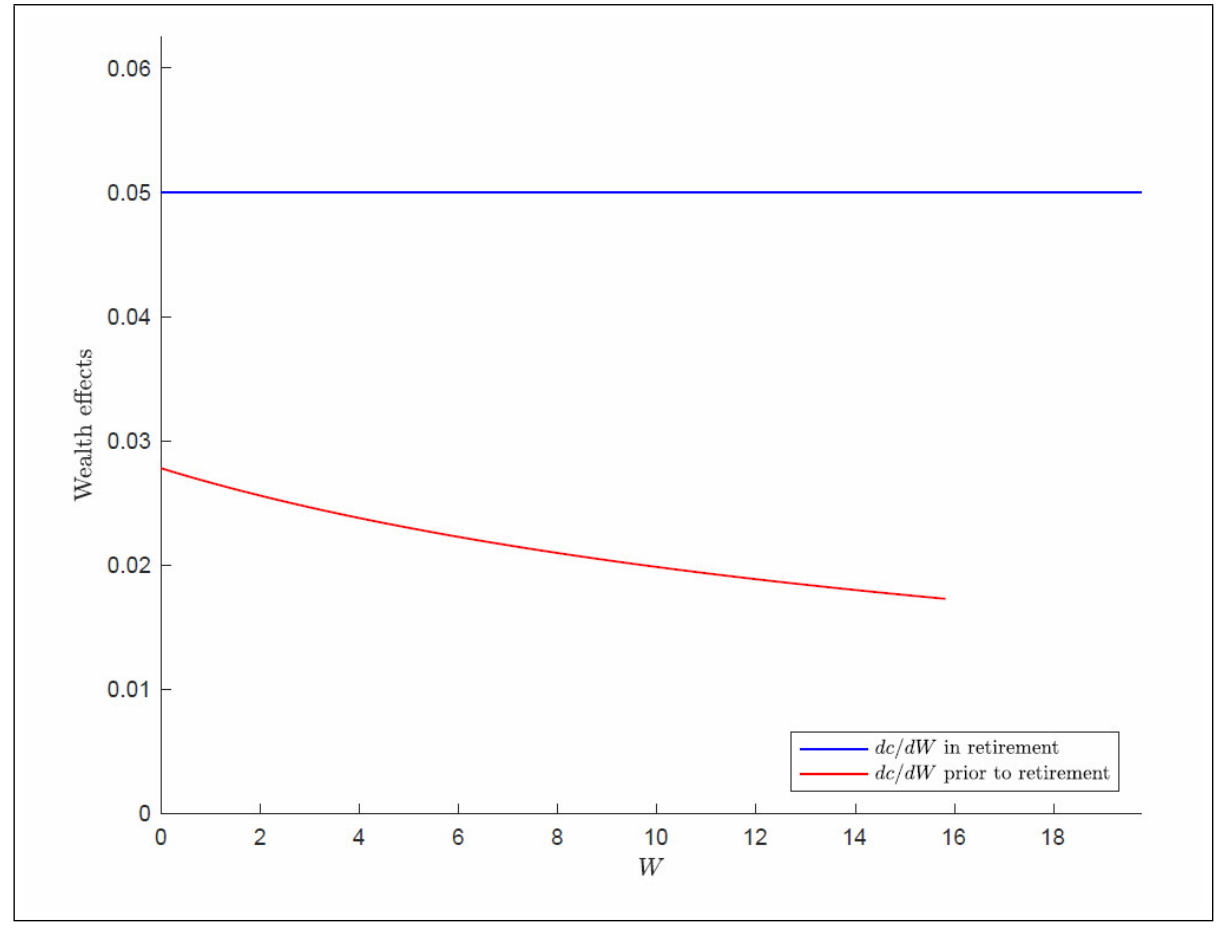

return shocks were fully absorbed by the changes in expected utility from leisure. Here, the offsetting effect is present but smaller than one-to-one, which gives rise to wealth effects for consumption that are positive but smaller than $r$.

The decreasing pattern of wealth effects prior to retirement, observed in Figure 4, can be understood in terms of the less than one-toone response of the value of human capital and the associated change in the expected present value of leisure in retirement. When the agent's financial wealth is low, she plans to work for a long duration, and the present value of her retirement leisure is low. By adjusting her already far-off retirement date, the agent can change the value of her human capital by a little and thus is able to transmit only a small portion of the financial return risk to the value of her retirement leisure, which leaves her consumption relatively more exposed and makes wealth effects relatively strong.

When the agent's wealth is close to the retirement threshold, she plans to work for just a short time, and the present value of her retire- 
Figure 5 Total Wealth

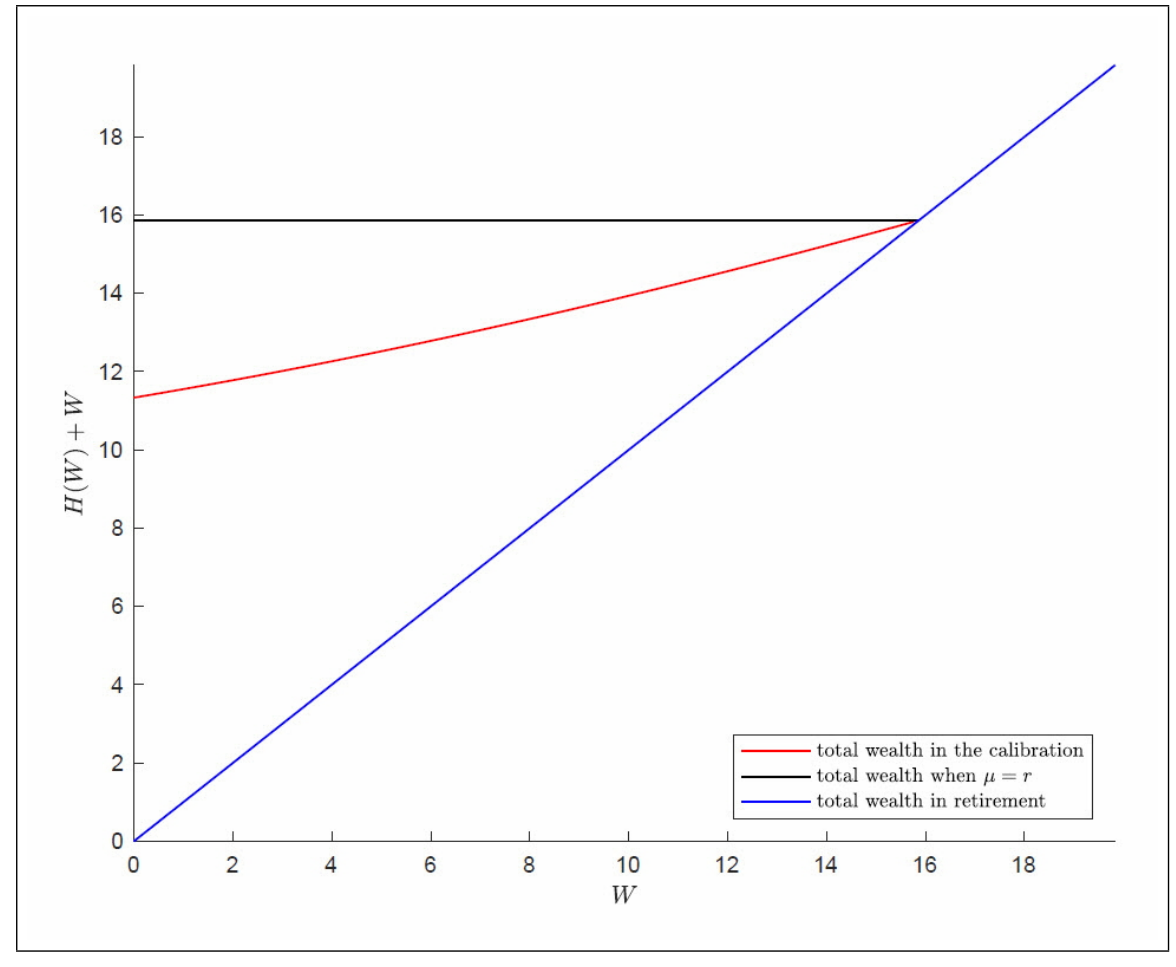

ment leisure is high. By adjusting her retirement date in response to realized financial return shocks, the agent can change the value of her human capital drastically and thus is able transmit a lot of the financial return risk to the value of her retirement leisure, which insulates her consumption better, yielding a weaker wealth effect. Intuitively, the value of human capital is "less endogenous" when retirement is far off and "more endogenous" when retirement is near.

As the agent retires, she loses completely the ability to adjust the value of her human capital or the present value of her retirement leisure. This means all the financial return risk must now be absorbed by consumption, leading to a jump in the wealth effects at retirement.

Figure 5 plots the agent's total wealth, $H\left(W_{t}\right)+W_{t}$. In the baseline example with no risk premium, as we saw in Section 7, the endogenous adjustment of the value of human capital perfectly offsets the shocks to financial wealth, so the agent's total wealth is constant, equal to $W^{*}$, at all times prior to retirement, and, consequently, the wealth effect is 
Grochulski \& Zhang: Wealth Effects with Endogenous Retirement 195

nil. In retirement, the value of human capital is fixed at zero forever, i.e., it cannot respond at all to shocks to financial wealth, and thus the effect of these shocks on consumption is strong. In the calibrated model, prior to retirement, we see that the agent's total wealth is a less steep function of $W$ than it is in retirement, but it is more steep than prior to retirement in the baseline case of $\mu=r$. Correspondingly, the wealth effect in the calibration is not as strong as in retirement but remains positive.

The same intuition also helps us understand comparative statics with respect to the retirement leisure utility flow $\psi$. The comparative statics result, which we can show numerically, is that higher $\psi$ leads to a lower average wealth effect. Intuitively, high $\psi$ means a lower threshold $W^{*}$, faster desired retirement, and thus a "more endogenous" value of human capital. With the value of human capital reacting to the wealth shocks more strongly, the agent can stabilize her consumption better, which explains a weaker average wealth effect of the financial return shock on consumption.

\section{CONCLUSION AND FURTHER READING}

In this article, we study a simple model of optimal consumption, saving, and retirement decisions. We use this model to show that the endogenous response of the agent's planned career length and the associated change in the value of her human capital dampen the response of consumption to financial return shocks. In a reasonable parametrization, the model is able to generate wealth effects of the magnitude observed in the data.

We make several simplifying assumptions that do not affect our main result. First, we abstract from portfolio choice, which makes the consumption-saving-retirement problem very easily tractable. Farhi and Panageas (2007) study a more general problem with an endogenous portfolio choice as in Merton (1971) and show that wealth effects are weakened by the endogeneity of the retirement decision also in their model. In addition, they show that the portfolio weight of risky assets is increased by the inclusion of this margin.

Second, we abstract from shocks to labor income and labor supply decisions on the intensive margin. It is easy to see that exogenous labor income risk would change the retirement threshold without affecting the result that the endogeneity of the value of human capital moderates wealth effects. Liu and Neis (2002) and Farhi and Panageas (2007) discuss the case with endogenous response of labor supply along the intensive margin. They show that wealth effects are lower than 
in retirement but not necessarily decreasing in wealth, depending on assumptions.

Third, we follow Kingston (2000) and Farhi and Panageas (2007), among many others, in modeling retirement as an absorbing state with zero hours worked, which is a strong assumption. Ruhm (1990) and Rust and Phelan (1997) show that less than 40 percent of workers retire from full-time career jobs by exiting the labor force completely. About half of the workers transition from full-time career jobs to parttime retirement "bridge" jobs. About 25 percent of workers experience episodes of reemployment after retirement. ${ }^{15}$ The assumption of a single transition into full retirement, clearly, helps keep our analysis simple. The intuition that arises out of our model strongly suggests, however, that more flexible retirement would help us generate low wealth effects. In particular, an option to unretire would make the value of the agent's human capital "more endogenous," allowing it to better absorb the financial return shocks and thus helping the agent stabilize her consumption, which would dampen the wealth effects of the financial return shock on consumption.

Further, we abstract from mortality risk, the bequest motive, and the possible nonseparability of utility between consumption and leisure. Dybvig and Liu (2010) include these features and show that the agent's consumption and portfolio allocation jump at retirement. Farhi and Panageas (2007) and Dybvig and Liu (2010) also allow for borrowing, i.e., negative wealth, subject to appropriate borrowing constraints. Each of these assumptions changes the results quantitatively but not qualitatively.

In other areas of economics, the endogeneity of the retirement decision has been shown to be important when assessing magnitudes of various economic forces. For example, Rogerson and Wallenius (2013) show its importance for measurement of the intertemporal elasticity of substitution for labor supply. Ndiaye (2018) shows its importance for calibrating optimal labor income tax rates and Social Security benefits.

\footnotetext{
${ }^{15}$ However, based on evidence from the Panel Study of Income Dynamics and the Current Population Survey, Rogerson and Wallenius (2013) argue that an abrupt transition from full time to little or no work approximates well the process of retirement for male heads of households in the US.
} 
Grochulski \& Zhang: Wealth Effects with Endogenous Retirement 197

\section{APPENDIX: PROOF OF LEMMA 2}

Define a bounded random variable $M:=\int_{0}^{\infty} r e^{-r t} 1_{t<\tau} d t$ and a martingale $M_{t}:=\mathbb{E}_{t}[M]$. We have $M_{t}=\int_{0}^{t} r e^{-r s} d s+e_{t}^{-r t} \mathbb{E}_{t}\left[\int_{0}^{\infty} r e^{-r s} 1_{t<\tau} d s\right]=$ $1-e^{-r t} G\left(W_{t}\right)$. The drift of $M_{t}$ is $r e^{-r t} G\left(W_{t}\right)-e^{-r t} G^{\prime}\left(W_{t}\right)\left(\mu W_{t}+y-\right.$ $\left.c\left(W_{t}\right)\right)-\frac{1}{2} \sigma^{2} W^{2} e^{-r t} G^{\prime \prime}\left(W_{t}\right)$, which must be zero. QED 


\section{REFERENCES}

Benzoni, Luca, and Olena Chyruk. 2015. "The Value and Risk of Human Capital." Annual Review of Financial Economics 7: 179-200.

Bewley, Truman. 1977. "The Permanent Income Hypothesis: A Theoretical Formulation." Journal of Economic Theory 16 (December): 252-92.

Cagetti, Mariacristina, and M. De Nardi. 2008. "Wealth Inequality: Data and Models." Macroeconomic Dynamics 12 (September): $285-313$.

Calomiris, Charles W., Stanley D. Longhofer, and William Miles. 2012. "The Housing Wealth Effect: The Crucial Roles of Demographics, Wealth Distribution and Wealth Shares." Working Paper 17740. Cambridge, Mass.: National Bureau of Economic Research (January).

Dixit, Avinash K. 1990. Optimization in Economic Theory, Second Edition. Oxford: Oxford University Press, 164.

Dixit, Avinash K. 1993. The Art of Smooth Pasting. New York: Gordon and Breach Publishing Group, 88.

Dybvig, Philip H., and Hong Liu. 2010. "Lifetime Consumption and Investment: Retirement and Constrained Borrowing." Journal of Economic Theory 145 (May): 885-907.

Farhi, Emmanuel, and Stavros Panageas. 2007. "Saving and Investing for Early Retirement: A Theoretical Analysis." Journal of Financial Economics 83 (January): 87-121.

Friedman, Milton. 1957. A Theory of the Consumption Function. Princeton: Princeton University Press.

Grochulski, Borys, and Yuzhe Zhang. 2013. "Saving for Retirement with Job Loss Risk." Federal Reserve Bank of Richmond Economic Quarterly 99 (First Quarter): 45-81.

Hall, Robert E. 1978. "Stochastic Implications of the Life Cycle-Permanent Income Hypothesis: Theory and Evidence." Journal of Political Economy 86 (December): 971-87.

Iacoviello, Matteo M. 2011. "Housing Wealth and Consumption." Board of Governors International Finance Discussion Paper 1027 (August). 
Grochulski \& Zhang: Wealth Effects with Endogenous Retirement 199

Kamien, Morton I., Nancy L. Schwartz. 1991. Dynamic Optimization: The Calculus of Variations and Optimal Control in Economics and Management, Second Edition. Amsterdam: Elsevier, 261.

Kaplan, Greg, and Giovanni Violante. 2014. "A Model of the Consumption Response to Fiscal Stimulus Payments." Econometrica 82 (July): 1199-239.

Karatzas, Ioannis, and Steven E. Shreve. 1998. Brownian Motion and Stochastic Calculus, Second Edition. New York: Springer Science+Business Media, Inc.

King, Mervyn, and David Low. 2014. "Measuring the 'World' Real Interest Rate." Working Paper 19887. Cambridge, Mass.: National Bureau of Economic Research (February).

Kingston, Geoffrey H. 2000. "Efficient Timing of Retirement." Review of Economic Dynamics 3 (October): 831-40.

Lettau, Martin, and Sydney Ludvigson. 2004. "Understanding Trend and Cycle in Asset Values: Reevaluating the Wealth Effect on Consumption." American Economic Review 94 (March): 276-99.

Liu, Jun, and Eric Neis. 2002. "Endogenous Retirement and Portfolio Choice." UCLA Working Paper.

Merton, Robert C. 1971. "Optimum Consumption and Portfolio Rules in a Continuous-Time Model." Journal of Economic Theory 3 (December): 373-413.

Ndiaye, Abdoulaye. 2018. "Flexible Retirement and Optimal Taxation." Federal Reserve Bank of Chicago Working Paper 2018-18 (November).

Piazzesi, M., and M. Schneider. 2016. "Housing and Macroeconomics." In Handbook of Macroeconomics, Vol. 2, edited by John B. Taylor and Harald Uhlig. Amsterdam: Elsevier, $1547-640$.

Pindyck, Robert S. 1991. "Irreversibility, Uncertainty, and Investment." Journal of Economic Literature 29 (September): $1110-48$.

Poterba, James M. 2000. "Stock Market Wealth and Consumption." Journal of Economic Perspectives 14 (Spring): 99-118.

Rogerson, Richard, and Johanna Wallenius. 2013. "Nonconvexities, Retirement, and the Elasticity of Labor Supply." American Economic Review 103 (June): 1445-62.

Ruhm, Christopher J. 1990. "Bridge Jobs and Partial Retirement." Journal of Labor Economics 8 (October): 482-501. 
Rust, John, and Christopher Phelan. 1997. "How Social Security and Medicare Affect Retirement Behavior in a World of Incomplete Markets." Econometrica 65 (July): 781-831.

Saez, Emmanuel, and Gabriel Zucman. 2016. "Wealth Inequality in the United States since 1913: Evidence from Capitalized Income Tax Data." Quarterly Journal of Economics 131 (May): 519-78.

Stokey, Nancy L. 2009. The Economics of Inaction. Princeton: Princeton University Press.

Zhao, Bo. 2018. "Too Poor to Retire? Housing Prices and Retirement." Review of Economic Dynamics 27 (January): 27-47. 